Darwin and other Victorian writers simply assumed that organic matter would accumulate in the absence of life. In the second half of the last century, the non-biological formation of organic molecules was well known. Sugars condensed from formaldehyde, the complex miscellany called "azulmic acid" condensed from cyanides, and every unskilled chernist was plagued by the ready formation of polymeric tars. Coping with complexity rather than simplicity would have been the main problem confronting a primitive organism. All this is now being systematized and Oparin gives a useful survey of the types of synthesis occurring when different mixtures of simple substances are exposed to different sources of encrgy. It seems safe to conclude that, within broad limits, a proposed scheme of biopoiesis that necessitates the presence of some particu. lar type of molecule could hardly be faulted on chemical grounds.

That much is factual: these substances exist. 'Their integration into a quasi-organism, or eobiont, is speculative. Oparin makes many sensible suggestions about interactions between catalytically active colloidal systems to their mutual advantage, about the manner in which such a heterogeneous system could cvolve, and about the meaning to be given to the concept of selective advantage in it. Research on this aspect of biochemistry will probably be rewarding. No one expccts Faust's homun. culus to jump out of the bottle, but it should be possible to get some progressing patterns of integrated catalysis.

A monoglot reviewer, confronted by a translation, cannot assign responsibility for ambiguity, confusion and infelicity. There are some obscure passages in the section on the evolution of autotrophism and acrobie life for which Oparin may not be responsible. But he probably is responsible for calling the postulated quasi-living forms "protobionts". The cquivalent word may be acceptable in Russian, but in Fnglish the word is pre-empted as an alternative to protozoa and there will be confusion if attempts are made to give it another meaning.

N. W. Pirie

\section{ALL IN THE MIND}

\section{Mind and Body}

By Stephen Black. Pp. $318+11$ plates. (Kimber: ILondon, April 1969.) $63 s$.

THe central message of this book may be expressed in two ways. One is that there is "a connexion between the brain ... and ... the most serious psychosomatic symp. toms". The phrase quoted is a comment on the finding that gastric uleers can be induced by certain experimental procedures only if the nerve supply to the stomach is intact. The second is implied later in the samo passage, where it is concluded that "both the stomach and ... duodenum are more intimately associated with mind than most of the anatomy". Dr Black, then, in these passages at least, assumes the existence of mind as an agent acting to varying extents on the body, and acted upon by the outside world, but separate from the bodily structures which are directly accessible to enquiry. In another place, however, "mind is the informational system derived from the sum improbability of form inherent in the structure of living things", and in yet another there is a reference to "the personality, or mind". But the observations which are held to demonstrate the action of psyche on soma are evidently those in which the brain has been shown to influcnce certain bodily processes.

These processes fall into two groups. 'The first consists of the diseases commonly described as psychosomatic; among these, Black includes tuberculosis. The second comprises the phenomena of immunity and allergy, especially allergic skin conditions. Black gives a readable, documented account, most of it suitable for the general reader, of both sets of phenomena, including a quite technical, brief review of the diseases attributed to autoimmunity. There are good descriptions of some of the more bizarre psychosomatic effects, such as the appearance, after one condition has been cured, of a completely new, apparently alternative, set of symptoms. His discussion of the criteria on which to base a diagnosis of psychosomatic disease is uscfully critical, though some of his views are unconventional. For instance, he regards prolapsed intervertebral disk as psychosomatic because (he states) for this condition no "physical pathology is really 'known'". Black often uses quotation marks in this way where an explanation of his meaning would be more helpful.

The best part of the book is a detailed and cnjoyable narrative of researches, carried out by Black and his colleagues, on the effects of hypnosis on the response of the skin to allergens. The description of the methods and scope of hypnosis is lucid and balanced. The experiments in which hypnosis was used illustrate the influence of the central nervous system (or mind ?) on eczematous and urticarial lesions. In other experiments on hearing, hallucinations were induced by hypnotic suggestion and some of the resultant central nervous changes recorded.

While Black is evidently a rigorous experimentalist, he is dogmatic in other respects. He writes that "only psychoanalytic interpretation of the unconscious motivation" which underlies peptic ulceration can "provide evidence of the necessary conflict-since the conflict itself is entirely unconscious". He also refers to "the all-important unconscious mind of the Freudians" and equates it with Jung's "collective unconscious". 'There is no hint of the difficulties of applying these notions in practice, and little indication of the controversies which they have aroused.

The least satisfactory feature of the book is the treatment of theoretical concepts. The first four chapters, in which Black tries to define life and mind, and discusses the history of monistic and dualistic modes of thought, are likely to confuse and deter many readers. Black makes frequent reference to "Aristotelian forms" and writes of "my new scientific unity of mind and body", but he doos not do justice to modern attempts to throw light on his subject. The contributions of Gilbert Ryle and his opponents are not acknowledged.

Shorn of its obscurities, Mind and Body could make absorbing and instructive reading for a wide public. If it is reissued as a paperback, the author should perhaps not shrink from drastic surgery.

S. A. BARNETT

\section{MUSCLE FOR STUDENTS}

\section{Muscles, Molecules and Movement}

An Essay in the Contraction of Muscles. By J. R. Bendall. (Heinemann Studies in Biology, No. 6.) Pp. $x x+219$. (Heinemann (Educational): London, March 1969.) $35 s$.

For a long time I have been wanting a book for second and third year undergraduates in biology, biochemistry or physiology which covered all aspects of muscle and did not stop at the artificial borders of these subjects. This book in large measure meets these demands.

This is not the book for the complete beginner in muscle (for him the paperback by Wilkie gives an excellent introduction to the fiold). 'Thus, although the structure of the myofibril and the sliding of filaments are introduced, $T$ doubt if the novice could take it in. And one or two terms such as superprecipitation are mentioned without definition. But, after an introductory course, the student will be able to find stimulating recding here.

Dr Bendall is not up to his later form in the chapter dealing with the molccular biology of muscle. We are fairly rushed through all the latest advances in the ultra- 